\title{
Coercion, Value and Justice Redistribution in a Neutral State
}

\author{
Michael Hemmingsen
}

\begin{abstract}
I argue that a commitment to liberal neutrality, and an opposition to coercion, means that we ought to support a redistributive state in which wealth, insofar as it is instrumental in allowing us to pursue our ends, is equalised. This is due to the fact that any conception of justice and desert works in favour of some, but against others, and that those who lose out by any particular conception are likely not to consent to it (meaning that its imposition is coercive). As having some understanding of justice and desert is inescapable in a society, coercion is unavoidable. However, those who are harmed by the imposition of a certain conception of justice and desert deserve compensation for their foregone position in the alternate conceptions in which they would be better off. This compensation is owed by those who have benefitted from the existing conception of justice and desert.
\end{abstract}

Keywords: coercion, desert, libertarianism, neutrality, Nozick, Rawls, redistribution, Wolff

\section{Introduction}

The contrast between libertarianism and more liberal egalitarian views is often seen as a matter of differing fundamental premises: libertarians see only negative rights as legitimate whereas liberal egalitarians, for instance, support the kinds of positive rights that lead to redistribution. Libertarians emphasise liberty, and those more on the left emphasise equality. Unless one can persuade the other to change their fundamental views, it is difficult to see how we can get beyond this impasse. A better strategy, if it can be made to be successful, is to show that the fundamental assumptions of one side of the debate actually lead to the more substantive policies of the other. That is, to change the others' views on political practice while allowing them to keep their fundamental political ideals intact. James P. Sterba, for example, takes up this strategy when he argues that libertarian concern with negative rights makes it just as acceptable for the poor to take from the rich as it is for the rich to hold onto what they have. In cases where the poor need to take from the rich in order to survive, he says, 'the liberty of the poor is at stake in such conflict situations. 
What is at stake is the liberty of the poor not to be interfered with in taking from the surplus possessions of the rich what is necessary to satisfy their basic needs' (Sterba 2010: 14). If there is a conflict of liberties, he argues, we ought to favour those who are not meeting their basic needs rather than those who have a surplus.

However, insofar as Sterba's argument is intended to be persuasive to libertarians themselves, rather than providing an argument for supporters of redistribution as to why they should continue with their current practices, it is not successful. Sterba misses key features of the libertarian position, namely the concepts of desert and non-coercion. In a clash between those with not enough and those with a surplus it is relevant to the libertarian how the initial distribution came about. If the wealth of the rich was accumulated due to voluntary exchange, then they deserve the wealth they have. On the other hand, the only way the poor can gain the wealth of the rich is through aggressive, coercive action. They are not entitled to the surplus wealth of the rich to begin with, and coercing the rich to get it would be illegitimate (Narveson 2010: 169). Therefore, the right of the rich to keep what they have, based as it is on the desert that flows from non-coercive exchange, trumps the right of the poor to take what they need, as such an action can only ever be coercive. While a superficial understanding of negative rights might suggest that redistribution of wealth is legitimate, the underpinning of such rights by the principle of non-coercion, and the idea that distributions brought about through non-coercive exchange are a matter of desert, shows that this claim is unwarranted.

I take the two ideas of desert and non-coercion to be fundamental to libertarianism; more so, certainly, than that of negative liberty, as key as such a concept is in libertarian thought. Yet, Sterba's strategy of attempting to turn key libertarian principles against libertarian practical policy, and towards a more redistributive policy, is an attractive one. A better strategy to follow through on Sterba's intention, then, would be to draw redistributive implications, if possible, from these more fundamental libertarian concepts. Hence, in this paper I argue that, if we are committed to the view that coercion is illegitimate - as libertarians are - and that we should not impose our views on others by substituting our ends for theirs, we ought to support significant redistribution of wealth - in principle, redistribution to the point of equality. Once we recognise that any particular set of social rules (including the libertarian) is coercive, we are forced to recognise duties of compensation to those who are worse off than under alternate conceptions by the instantiation of any particular view. (I mean 'worse off' in terms of the ability to achieve our ends, regardless of what they may be.) I argue that this duty is owed by all who benefit from a certain state of affairs, as compared to how they would have been under any alternative conception in which they would have been worse off, and in which others would have been better off (compared to their current position). This leads to, I argue, a strongly egalitarian system in terms of the distribution of wealth and power, and does so while maintaining the core libertarian doctrines. 


\section{Neutrality}

One of the central aspects of libertarian political philosophy is an opposition to coercion. Libertarianism is, at heart 'a philosophy of personal liberty - the liberty of each person to live according to his own choices' (Hospers 1971: 5). We are beings 'capable of choosing autonomously among alternatives' (Nozick 1974: 48) and our choices are constitutive of our identity. Furthermore, we each lead a separate life to all others, and no one can legitimately 'interfere with someone else's shaping of his own life' (Nozick 1974: 50). Liberty of thought as well as action is fundamental. To coerce others to live according our own idea of the good life is to do them a serious harm. This is why libertarian parties tend to take pro-choice positions on abortion (Libertarian Party 2014), are for equality for homosexual, polygamous, and other sexual relationships that are have formerly not had, or do not yet have, legal recognition (Libertarianz 1994), and support drug legalisation (BCLP 2013).

In short, libertarianism takes the view that we should not impose our own conceptions of the good on others. Tax, for example, is problematic, as it unjustly takes from one individual their deserved wealth - thereby preventing them from disposing of it in a way that is in accordance with their values and that brings about their chosen ends - in order to promote the aims of others, such as socialised medical care, social welfare payments, grants for artists and public art, and so on. In fact, taxation is equated with forced labour (Sterba 1978: 117). As Robert Nozick puts it, as '[t]here are only individual people, different individual people, with their own individual lives', then

[u]sing one of these people for the benefit of others, uses him and benefits the others. Nothing more. What happens is that something is done to him for the sake of others ... To use a person in this way does not sufficiently respect and take account of the fact that he is a separate person ... He does not get some overbalancing good from his sacrifice, and no one is entitled to force this upon him. (Nozick 1974: 33)

Taxing some to provide for others is therefore coercive and unjust, as it imposes one person's will on another. It is central to the libertarian ideal that individuals should be able to be free to choose their own good, and should not have the pursuit of their own good circumscribed in any way by the coercive actions of others. For the libertarian, we cannot expect others to forego their interests to enable us to pursue our own without their consent. If we propose a certain way of organising society, even if it is better for the majority, we cannot expect those who are made worse off to accept such a social system merely on the grounds that it is the best 'overall'. Interests cannot be aggregated, such as in a utilitarian calculus; no possible benefit to myself can justify a harm to another without their consent (which, of course, they are under no obligation to give).

However, while libertarians tend to view their political philosophy as being free of coercion - all interactions take place between equals, and the outcome 
is brought about through the consent of all parties, I would argue that libertarianism is not as free from coercion as it claims. In fact, it could be said to be no less coercive than many accounts involving a central government that redistributes wealth. When comparing libertarianism to alternative ways of organising society, the issue is not whether or not there is coercion in one conception or the other - there is always coercion: the question is who is being coerced, to do what and for what reason. Certainly, a redistributive government coerces those with wealth in order to provide certain goods and services for others, regardless of whether the wealthy consent to such a redistribution. Similarly, however, in a libertarian society those with wealth are in a position to coerce those placed more precariously. The precariousness of workers, for example, gives the more financially secure employers the ability to coerce them into accepting contracts that they would never accept had the relationship been a more equal one. Or, for instance, the wealthy are in a position to determine the nature of shared social space through their ownership of the land and the means to build on it, thereby foreclosing the ability of others to control the nature of their environment. In general, choice is reduced as decisions that could be made through systems of social choice and compromise are withdrawn from the majority of the public and placed in private hands. We might make an argument that one or the other instance of coercion is legitimate, but doing so presumes that a particular conception of legitimacy has been agreed to. While it is presumably possible for this agreement to take place, there does not seem to be any way of establishing a priori which system of social organisation will be chosen (barring Rawls's dubious, purely gametheoretic model of deciding, which he later repudiated) (Rawls 1951, 1957, 1971; Wolff 2013).

As such, we ought to think about the libertarian world not as a neutral option, but as one possible way among many that we could understand how, and on what basis, we should distribute wealth and power (and hence the ability of individuals to achieve their ends). The libertarian holds certain views about private property, about desert, and about just distribution, but it is one view only, and should not be treated, without first achieving the assent of all those affected by the instantiation of this system, as having any special status. We could hold that those who deserve the wealth and power are those who contract for it in a marketplace in which there is no government intervention and no collective decision-making, but we could also hold that those who deserve the wealth and power are those who have the greatest moral worth (however this is determined), or those who need it, or those who have acquired the greatest training or education, or we could distribute according to the value of what an individual produces (for example, the worker rather than the capitalist is entitled to the full surplus value created by their labour), or any other principled take on how we ought to organise the distribution of wealth and power (Nozick 1974: 154-6). There are far, far more possibilities than I am able to list here. 
Looking purely at the distribution of society's wealth (wealth being in any case connected to an individual's ability to pursue their ends), we could imagine a wide range of different ways of understanding justice in distribution than the libertarian one - or our current one - and each different account benefits various individuals differently. For example, rather than a market-based account of value, we could compensate based on the unpleasantness of the work (highly valuing janitors, sewerage workers, etc.), or social necessity (teachers, care workers, stay-at-home parents), risk (miners, police, soldiers), or physical difficulty (labourers, high-level sportspeople), and many other accounts besides. Any set of principles of desert, justice, and so on, principles that underlie our laws, inevitably shapes the distribution of wealth in a society. As Michael Blake points out, the laws and principles we use to decide on value and desert

define, collectively, what sorts of entitlements will exist in our society; they determine what shall count as property, what sorts of private agreements will receive public enforcement ... This pattern ... defines how we may hold, transfer, and enjoy our property and our entitlements. In so doing ... [they] create a pattern of entitlements [and define] how property will be understood and held, and what sorts of activities will produce what sorts of economic holding. (Blake 2001: 281)

According to the libertarian account, desert for labour is based on the market value of the activity, and laws exist to ensure a certain form of contracting can take place between parties. But of course this is only one view of a wide possible set of equally valid accounts. It is worth pointing out how odd, and arbitrary, a market-based account of value is. In answer to the question, 'Why is the market value the appropriate way of valuing?' the libertarian, I believe, would say, 'Because it is the value of the good in an uncoerced exchange.' But then, if we ask, 'Why is the value of something the value it holds in an uncoerced exchange?' it is difficult to see how to answer, aside from simply baldly asserting something like, 'Because that is what value is', which is of course unsatisfying to those who disagree, or by holding that uncoerced exchange is the best mechanism for capturing a sense of value that is defined independently of the exchange. But this means that market value is only a proxy for some other kind of value. Perhaps, they might say, the value in market exchange is a way of capturing someone's efforts plus their talents, in which case we are valuing hard work and talent. This leads us to ask whether market exchange really $i s$ the best way of capturing the amount of effort and talent put into the objects of exchange. Furthermore, market-based value famously does not allow us to value things properly in a way that many feel we ought to: homemakers, for example, are not compensated for their labour, as it has no market value, leading to the implicit view that this labour is valueless. Many would not, however, want to say that such labour is valueless, even if it is treated as such. Environmentalists, too, argue that people value the natural 
environment in a way that is not reducible to what we would choose to (or are able to) pay for its preservation in the market (Beckerman and Pasek 1997). Contingent valuation based on stated preference models that are the outcome of surveys asking questions such as 'How much would you pay to preserve the natural environment?' are only answerable for some when they are forced to provide an answer; many would not want to think of the natural environment in utility or market terms at all. An account that values only according to market exchange value is a conception that values some things (freedom, in a particular, and contestable, sense of that term) and devalues others: it is not a neutral criteria of valuing, and nor are the laws that stem from it neutral laws.

Regardless of which account we accept of justice in distribution, however market value, contribution value, moral value, need, necessity, difficulty, and so on - and no matter what set of principles we choose to underpin our laws, we fail to reach a value-neutral account. All impose a view of the good - of desert and justice - on others who might not agree. As Nozick recognises, 'The best of all possible worlds for me will not be that for you. The world, of all those I can imagine, which I would most prefer to live in, will not be precisely the one you would choose' (Nozick 1974: 298). Unfortunately, however, all of these different accounts are all-or-nothing: if we accept an account that distributes on the basis of (for instance) the surplus value created by the individual, we are not thereby open to also institute a system based on distributing on the basis of market exchanges, or on the basis of virtue, and so on. After all, if we tried to institute more than one system in a particular society, how would we deal with situations in which the value given in a free market exchange does not match their created surplus value (as it frequently will not)? Ultimately we have to go with one or the other approach. And of course, as Blake points out, 'there is nothing natural or obvious' (Blake 2001: 278), in our current system, and no reason to value it simply because it is the one that currently exists (that we ought to value what happens to exist above all is something that requires uncoerced agreement, which is not likely to be given by those who oppose the status quo). It is not at all clear why, then, we should agree to a particular set of principles, particularly when those principles work against us, whether we are talking about our actual situation or a hypothetical, alternate social system. A libertarian account does not help us here, as it forecloses the other alternatives in exactly the same way, and with as much (or as little) justification.

When we consider that there is an extremely diverse range of accounts of justice in distribution and compensation, as well as proposals for shared laws (and the principles that underlie them), we are left with a problematic state of affairs. It is impossible to have no principles of justice in distribution and compensation, contract law, taxation, and so on, in society. Even if we were to leave things alone and enter a state of nature, we are still operating on the principle of 'take what you can get away with', which is of course a principle likely to be opposed by many. However, it is clear that there is no such thing 
as a neutral account. Whichever account we choose, we impose that view of justice on individuals who might not agree to it. So, it is quite impossible to have no principles of justice, impossible to have a range of conflicting principles of justice, and yet we cannot settle on any particular account, including the libertarian one, without coercing those do not agree with it. What are we to do, then, if we want to create a society that does not force one conception of the good on others? It seems an impossible task. Rawls, of course, builds from an overlapping consensus - but even this assumes certain values are already shared (and presumably where they are not, that they ought to be). If we are to construct a social system that everyone agrees to (and to say that people ought to agree is not sufficient, as it presumes certain standards of assessment that have not been assented to, and are hence coercive) we must avoid assuming any substantive moral view entirely.

Let us imagine that we are choosing the concepts of justice. As mentioned, we cannot each have our own different ideas of justice in practice - what is characteristic about such rules is that they operate across a society - yet we also have to choose some account; that is, one and only one conception of justice. If we assume that all of the options on the table are equally valid, as I think we must (it is impossible to assess such conceptions of justice as valid or not, I argue, without sneaking in some moral, and hence contestable, content to begin with, which themselves require a further justification that others are likely to object to), then the choice of any one conception is a harm to all those who do not support it, both in that they are having a conception they do not agree with imposed on them, as well as in regard to the forgone status, wealth and power they might have enjoyed under alternative conceptions of justice (and value and desert).

So, we choose one idea of justice; this is unavoidable, but also unavoidably harms. Hence, our focus should be on what we ought to do when we harm others, rather than in how to somehow choose without choosing, as the libertarian view (mistakenly) thinks it is doing. As when selecting between conceptions of justice in distribution, we cannot choose one conception of what we ought to do in cases where individuals have been harmed (I will refer to such a system as a 'principle in harm') without excluding a wide range of other, plausible principles. Neither can we choose no principle: what we imagine to be no principle is in fact a principle in disguise - it says that might wins the day. But, unlike when choosing our conception of justice in distribution, value and desert, we cannot take things back a step: if choosing a principle in harm harms those who disagree with the principle, then we must take things back a further step and decide how to adjudicate this harm, which necessitates an even further step back to decide on the rules for doing so, which in turn harms in its imposition, and so on, ad infinitum. Hence, we are forced to consider our principle in harm as basic, and decide on its content in another way.

I put forward the principle of compensation: when we harm others unavoidably we ought to compensate those harmed to the extent that they have lost 
out due to our harming. Nozick certainly agrees with this view - regarding the harm of pollution, for example, he states that 'If a polluting activity is to be allowed to continue ... then those who benefit actually should compensate those upon whom the pollution costs are initially thrown' (Nozick 1974: 80). So not only do libertarians already agree that harm ought to be compensated, an argument can be made for compensation for harm in terms of self-interest, à la Hobbes: after all, surely we would support, out of self-interest, a principle of compensation such that coercion, if it does occur, does not ultimately end up impacting significantly on our ability to pursue our ends. This principle is not really an imposition; you cannot claim not to desire a situation that would maximise your ability to pursue your ends - having ends without desiring to achieve them would be very strange; a failure of practical reason. I propose, therefore, that it is a principle of compensation for coercive harm that we apply to the outcome of our choice of a conception of justice: while we can choose only one way of organising society, we can compensate those harmed by this necessity to the extent of their harm.

\section{Who Is Harmed, and Who Harms?}

When it comes to understanding restitution, we need to decide who owes, and who is owed. David Miller outlines various ways in which we can understand the connection between ower and owed, or harmer and harmed, but I want to focus here on that of benefit. According to Miller, the identification of who benefits by actions is relevant in cases where $A$ 'has played no causal role in the process that led to $P$ 's deprivation', and so cannot be held responsible in that regard - after all, as the choice of state of affairs $x$ is a hypothetical rather than actual decision, it is hard to see how we could think of it in terms of causation. Similarly, $A$ does not bear moral responsibility for the situation: though $A$ may be considered to be morally responsible for the harm in the sense that the harm is a set of social institutions, and social institutions only persist due to our continuing support of them, it would be pushing things to argue that $A$ has brought about a state of affairs $x$, in the sense we usually use when talking about moral responsibility. Once again, the selection of $x$ from among the alternatives is a hypothetical one $-A$ was never actually in the position to choose $x$. Even though they may be responsible in part for the persistence of $x$, it would not be accurate to say that they were responsible for $x$ coming about in the first place. In short, moral responsibility cannot fully capture the hypothetical nature of the choice of $x$. Rather, when $A$ has 'benefited from [a] process - for instance, resources that would otherwise have gone to $P$ have been allotted to $A$ ', we ought to compensate them. 'In these circumstances, $A$ is not responsible for $P$ 's condition in [a moral or causal sense], and yet indirectly he is linked to that condition. He is an innocent beneficiary, let us assume, but the benefit would not have arisen unless $P$ had 
been deprived ... $[A]$ has been unjustly enriched by the train of events that led to $P$ 's being deprived, even though he himself has not behaved unjustly' (Miller 2007: 102-3).

Benefit captures the important features of this case, I argue, especially the hypothetical nature of the actions and the counter-factual nature of the harm. As the selection of any option rests on coercion, the fact that $A$ has been enriched (relative to equally valid alternative accounts) by an unjust state of affairs $x$ gives rise to their remedial responsibility to $P$, who has been deprived by $x$ (relative to where they would have been under equally valid alternative accounts).

\section{How Much Should We Compensate?}

We can only choose one conception of just distribution and of value. However, no matter what we end up choosing, we are harming those who would choose an alternative conception, and who would be better off under such an account (better off here being having more ability and opportunity to achieve one's ends). ${ }^{1}$ Since I am thinking of harm here as a loss in the ability to achieve one's ends, whatever they might be, we do not compensate merely because someone has not gotten their first choice of institutions. It may be the case that I prefer conception $x$, even though I would be better off, in terms of pure wealth, under conception $y$. However, if we are talking about the ability to achieve one's ends, whatever they may be, altruistic or selfish, then either I am better off under $y$ overall (in the sense of being able to maximally achieve my ends) or I suffer from a deficit of practical rationality: if I support $x$, knowing that it is not the best way of achieving my ends, including whatever otherdirected ends I might have, then I can only be irrational. As benefitting from a state of affairs, when such a state of affairs is coercively brought about, and when others have been deprived thereby, identifies one as responsible for compensating the harmed for their counter-factual loss, those who benefit (in terms of an increased ability to achieve one's ends) are obliged to undertake such compensation.

But there is a still further question of how much compensation is owed. According to Nozick, 'Something fully compensates a person for a loss if and only if it makes him no worse off than he otherwise would have been; it compensates person $X$ for person $Y$ 's action $A$ if $X$ is no worse off receiving it, $Y$ having done $A$, than $X$ would have been without receiving it if $Y$ had not done $A^{\prime}$ (Nozick 1974: 57). Since there is an extremely large - potentially infinite number of counter-factual options for distribution that are equally as legitimate as the one we end up instituting, each individual could have been vastly more well off than they end up in reality. So, we seem to be forced to say that everyone ought to be compensated up to the level that they would have been in the most favourable counter-factual. But of course this is ridiculous. While 
it would be lovely for everyone to be as well off as the most well off, this is hardly possible in practice: resources have their limit.

The solution, put simply, is to equalise income, insofar as that can equalise people's ability to achieve their ends. It may be argued here that equalising income is not the same as equalising ends. However, we have no means of comparing one person's ends to another's. Though one person's ends may be more resource-intensive than another's, this is not a reason to give them more resources, as we have no way of determining how their resource-intensive end is balanced against the less resource-intensive ends of others. All we can do, in practice, is distribute resources equally.

Let us imagine a situation in which $A$ has $\$ 15$, while $P$ has only $\$ 5 . P$ can, I argue, legitimately protest that they would have been better off under system $y$, rather than the reality, $x$, which made it possible for $A$ to make $\$ 15$. (At this point one could bring in the argument that $A$ earned their $\$ 15$, and that therefore they should be able to keep it. Certainly they undertook activities that led to their being rewarded $\$ 15$. However, if it is the very concept of how we value - what activities ought to be valued, and to what extent that is at issue, then it is a matter of dispute how much they deserve. Hence, we cannot claim ' $A$ deserves $\$ 15$ for performing $x$ ', without already settling the question of distribution and value.) Hence, $A$ ought to compensate $P$ to the extent that $P$ reaches the position they would have been in had the alternative $y$ been instituted.

So, let us say that $A$ gives $P$ their $\$ 15$, meaning that $A$ now has $\$ 0$, and $B$, $\$ 20$. Now, of course, $A$ can protest that under $x$ they would have been (and were) better off, meaning that $P$ now owes $A$ a duty of compensation. In this case, the duty of compensation only ends when both $A$ and $P$ have $\$ 10$, as $A$ cannot give $P$ another cent without making it possible for $P$ to claim compensation, and vice versa. Any inequalities, given the connection between wealth and the ability to achieve one's ends, give rise to a legitimate call for compensation from those with less to those with more. Hence, compensation is fulfilled when wealth, and therefore the commensurable proxy of our ability to achieve our ends, is distributed equally.

\section{Can We Have Any Inequality?}

Is any inequality in our ability to achieve our ends acceptable, then? Rawls, as is well known, has his Difference Principle: he argues that 'inequalities ... are just only if they result in compensating benefits for everyone, and in particular for the least advantaged members of society' (Rawls 1971: 13). The approach outlined in this essay has a similar implication, namely that inequalities are acceptable so long as no one is worse off than they would be under a regime of equal distribution of power. For example, once again using wealth as a proxy for the ability to achieve one's ends, if there is a total wealth of $\$ 250$ 
should the wealth be equally distributed, to be shared between five individuals (giving $\$ 50$ each), but $\$ 260$ if one individual is given $\$ 60$ (perhaps for being willing to take on a more difficult role than she would have been willing to for $\$ 50$, thereby increasing the overall wealth), then so long as the remaining wealth is distributed equally amongst the others, there is no problem. Any claim, legitimate or otherwise, on the extra $\$ 10$ by other members of the group would cause the extra wealth to evaporate (for example, the harder worker would be unwilling to take on the more burdensome, but more productive, role). In saying this, while there is likely to be some room for inequality, based on incentives, or for productive investments, it would be wise not to overstate the extent of this. There is some reason to think, for example, that beyond a certain point this kind of unequal rewarding is counter-productive, and that a distribution closer to equality would in fact generate more wealth overall (Tilly 2012). But some inequality is permissible, so long as it is limited to the amount necessary to increase the overall wealth by a certain amount, that no one is worse off, and that the surplus is evenly distributed.

\section{Conclusion}

If we are to avoid coercing others into adopting ends they would not otherwise choose, we need to remain neutral amongst the possible conceptions of social organisation. That is, if we are to avoid having our own principles of justice, conceptions of value, and so on, imposed on others coercively, we must acknowledge that all alternate conceptions are equally valid. The instantiation of one conception over another, in that it makes some individuals less able to achieve their ends, whatever they might be, without their consent, is a harm that, when inflicted on others, deserves compensation. The only way to reject the idea of compensation entirely is to act with a deficit of practical reason the idea of compensation guarantees that we will have the minimum of interference in our ability to achieve our ends, so it would be practically irrational to choose not to support it.

Since even an absence of explicit principles nevertheless leads to the principle of 'strength wins the day', it is impossible to escape having to choose one account of justice and desert over others. We cannot choose more than one, as either conflicts between the different conceptions have no means of arbitration, or such arbitration is in fact a conception of justice and desert itself. So, we must institute one, and only one, account, and as such we cannot avoid harming. Hence under all accounts those who benefit owe duties of compensation to those who are harmed. As we cannot compensate all to the extent of their harm (their foregone position in their top choice of alternative social arrangement) due to a lack of resources, the best we can do is to redistribute to a position of equality, so as to maximise each's ability to pursue their ends without asking any to pay a greater than average price for such a 
maximisation. In conclusion, even libertarians, to maintain their neutrality based on non-coercion, we are forced to acknowledge that we ought to redistribute, as a matter of compensation for harm, to a position of equality, or near equality, regardless of what kind of society we end up having. As such, redistribution of wealth is something that follows from libertarians' own principles; they are free (in fact, they ought to) support such policies, while still being able to hold onto their core values of liberty, non-coercion and desert.

Michael Hemmingsen is a Ph.D. candidate in the Department of Philosophy, McMaster University, and holds Master's degrees in Philosophy and International Relations from Victoria University of Wellington.

\section{Notes}

1. It might be objected here that the altruistic are disadvantaged in comparison to the selfish by the principle of benefit and compensation, in that the altruistic do not miss out on anything under any conception of desert and justice, whereas the selfish and grasping always would. Hence, the selfish deserve compensation under my account, whereas the altruistic do not. This would certainly be an undesirable implication. However, this criticism ignores the fact that the altruistic have ends just as the selfish do; their ends are other-regarding, but they are still ends. A loss in their ability to bring about such other-regarding ends harms them just as much as a selfish person who loses their ability to bring about their selfregarding ends. The important point in terms of harm and compensation is that our ends are being foreclosed, not what kinds of ends they are.

\section{References}

Beckerman, W. and J. Pasek. 1997. 'Plural Values and Environmental Valuation', Environmental Values 6(1): 65-86.

Blake, M. 2001. 'Distributive Justice, State Coercion, and Autonomy', Philosophy and Public Affairs 30(3): 257-96.

British Colombia Libertarian Party (BCLP). 2013. 'British Colombia Libertarian Party' http://www.libertarian.bc.ca/ (accessed 18 January 2014)

Hospers, J. 1971. Libertarianism. Los Angeles: Nash Publishing.

Libertarian Party. 2014. 'Platform.' http://www.lp.org/platform (18 January 2014) 
Libertarianz. 1994. 'Civil Unions.' http://www.libertarianz.org.nz/policies/civilunions/ (accessed 18 January 2014)

Miller, D. 2007. National Responsibility and Global Justice. New York: Oxford University Press.

Narveson, J. 2010. "The Issue Framed" in J. Narveson and J. P. Sterba, Are Liberty and Equality Compatible? Cambridge: Cambridge University Press. 123-182.

Nozick, R. 1974. Anarchy, State and Utopia. Oxford: Blackwell Publishers.

Rawls, J. 1951. 'Outline of a Decision Procedure for Ethics', Philosophical Review 60(2): 177-97.

Rawls, J. 1957. 'Justice as Fairness', Journal of Philosophy 54(22): 653-62.

Rawls, J. 1971. A Theory of Justice. Cambridge, MA: Belknap Press of Harvard University Press.

Sterba, J. P. 1978. 'Neo-Libertarianism', American Philosophical Quarterly 15(2): $115-121$.

Sterba, J. P. 2010. "The Practical Requirements of Liberty" in Jan Narveson and James P. Sterba, Are Liberty and Equality Compatible? Cambridge: Cambridge University Press. 7-39.

Tilly, C and Wood, L. 2012. Social Movements 1768 - 2012. $3^{\text {rd }}$ ed. Boulder: Paradigm Publishers.

Wolff, R. P. 2013. Understanding Rawls: A Reconstruction and Critique of A Theory of Justice. Wellington: Society for Philosophy and Culture. 